\title{
Historical Myths or Mythological History: A Fresh Approach to Understand the History of Assam
}

Dr Pranab Jyoti Sarma ${ }^{+}$

\section{Abstract}

This paper carries out a critical review of the trends of historical writings in Assam. The historiographical study reveals that the beginning of the historical phase was, in fact, late in the North East region. Moreover, in many of these historical writings, the importance of the local histories of the communities of the region was ignored. The author highlights the fact that a panIndian history for the region may not be authentic enough to understand the cultural dynamics of the complex society of the Northeast. The author also focuses on corroborating 'proper' historical source material for reconstructing the history of the region rather than deriving inferences from mythology and legends. However, the importance of recent trends in historiography such as selective utilisation of oral traditions, folklores and memory studies has been emphasised. An alternative and more precise periodisation of the historical phase has been provided which does not, however, project any clear marker between periods and eras but emphasises on slow and steady transformations. Importance of archaeological sources and material evidence has been kept in mind while deriving periodical divisions. Relooking at the history of the Koches, Kacharis has been emphasised.

Key words: Historiography, Kamarupa, Ahom, Kachari, Archaeology, Periodisation, Chronology

† Knowledge Manager, Indian Heritage Cities Network - IHCN, Mysore, India. Email: madhyaman@gmail.com (C)2014 Sarma. This is an Open Access article distributed under the terms of the Creative Commons Attribution License (http://creativecommons.org/licenses/by/2.0), which permits unrestricted use, distribution, and reproduction in any medium, provided the original work is properly cited. 


\section{Introduction}

While the growing boundary dispute between India and China was beginning to dominate the political and socio-cultural relationship between the two countries, Mao-ze-Dong once famously stated in front of a visiting Indian diplomat in Beijing that it was difficult to discuss history with the Indians as they often clash history with mythology. Although, Mao's statement has not been recorded anywhere and remains within the personal recollection of the delegate from the Foreign Ministry of India, what Mao observed has been reinstated time and again in Indian historical writings; Indians do have a general, well-known lack of historical consciousness. As has been observed by $E$. Sreedharan (2000: 309):

The central defect of the intellectual life of the ancient Indians, in spite of the antiquity and developed character of their civilization, is an almost complete lack of its historical and chronological sense.

Keith rightly observes that despite having a rich repertoire of literature, history is so "measurably represented...that in the whole of the great period of Sanskrit literature, there is not one writer who can be seriously regarded as a critical historian" (Sreedharan 2000: 309). A definite exception to this was the tradition of chronicling that came from Kashmir; the Rajatarangini of Kalhana being the most notable example. The medieval period of India is also historically well represented, thanks to the numerous chronicles written in either Persian or Arabic, which have almost unanimously set the chronological order of the Islamic rule in India beginning with the Delhi Sultanate, on a firm footing. Perhaps another such trend of historical chronicles, although much less known in the Indian context, comes from the region of Assam in the form of buranjis, the recordings of major political events by the Ahoms who ruled a major part of the Brahmaputra valley for almost six centuries since the early 13th Century CE.

Nevertheless, it is important to understand that all these three independent trends of historiography were not indigenous developments, but were rather influenced by trends of history writing of other regions. The Islamic historiography of medieval India was definitely a continuation of the trend in the Arab world, wherein the notion that everything civilized began from the coming of Islam remains the most dominant factor of chronology (Mukhia 1998: 93). In Kashmir, which was a zone of influence of the Arab world, the historiographical trend developed somewhat independently. Likewise, the trend of Ahom history writing was also a continuation of the practice of the Tai-Ahoms in their original homeland. The fact that Indians in general never had a strong historical sense needs no re-emphasis; most of the 'past knowledge' of Indians continued in oral traditions without any definite and well-structured sense of chronology. Although oral traditions and folklore played an important role, it is an irony that these are so glorified and mystified that it becomes difficult at present time to carve out a proper 'historical' and 'chronological' sequence out of them.

The first-ever effort of writing the Indian history came from the colonialists, when James Mill wrote six volumes of History in 1818. Mill classified the entire Indian history into three distinct periods: Hindu, Muslim, and Civilization (under the British rule). Mill's History relies heavily on the condemnation of the Hindus and the Muslims in order to highlight the significance of the British rule (Sreedharan 2000: 402-3). Mills was followed by many colonial historians and, later, by nationalist historians, who more or less followed the chronological paradigm provided by Mill, however changing the nomenclature to Early, Medieval, and Modern periods of Indian history. The fact remains that this tripartite division of Indian history has hardly been challenged or questioned by Indian historians, a case which is true for Assam, too.

Nationalist historians like H.C. Raychaudhury, R.C. Dutt, R.C. Majumdar, among others, were well aware of the problem of chronology of Indian history and have tried to provide a holistic understanding of the same in their invaluable works. All the available sources of Indian history, including the quasi-historical Puranas, the classical literature, and accounts of foreign travellers, apart from the available inscriptional evidence were utilised to come up with a standard chronological order. The dynastic history as laid out by Raychoudhury (1923) became the backbone for all future history writings. R.C. Majumdar's Cultural History of India also remains a notable contribution (Majumdar 1964). The sources of Indian history, however, have been so exhaustively utilised that, even Romila Thaper, one of the leading historians of India today, was forced to comment in the preface 
of her revised edition of Penguin History of India, that it was time to understand the importance of 'other' sources of Indian history (Thaper 1966/1976). She further emphasised that almost all the sources of Indian history had already been exploited and brought forth the importance of archaeological studies in order to restructure the conceptual frameworks of Indian history and culture.

The early as well as the late history of Assam and its adjoining areas have also been written on the basis of the conventional tripartite division of Indian history, and so have remained pan-Indian in its approach. A detailed look into the historiographical development of Assam since the colonial time is necessary here.

\section{Trends in Historical Writings on Assam}

The five-volume set of The Comprehensive History of Assam, edited by H.K. Barpujari, sums up almost all the known sources useful for the formulation of Assam's historical past and also provides a detailed description of the chronology that can be derived from these sources. However, the chronology more or less follows the division of history in the panIndian division of Early, Medieval and Modern periods. Barpujari's work is a continuation of the trend set by the nationalist historians, and even earlier by the colonialists.

Among the imperialist historians, the first mention must be made of Sir Edward Gait. His A History of Assam (1906) no doubt is one of the most important secondary sources for Assam's history, and has influenced generations of scholars. Gait was, however, not free from the assumption that the society at large in Assam during the pre-Ahom and the Ahom periods was static and the colonial rulers were the ones who could bring in drastic socio-economic change.

K.L. Barua's Early History of Kamarupa (1933) was one among the first few works that developed a distinctive trend of nationalist historians in Assam. Works of several other historians who followed this trend such as B.K. Barua $(1951,1952)$ and P.C. Choudhury (1959)-although important as they vividly recorded the political and the cultural history of Assam with the help of the available textual records and corroborating them with epigraphic and archaeological records-were not free from eulogising the achievements of the three main dynasties of Kamarupa (e.g., the Varman dynasty, the Salastambha dynasty and the Pala dynasty), the ancient name of Assam. History of the early period of Assam, as known and shown by the nationalist historians, was merely the dynastic history of Kamarupa.

There has been another notable trend within the nationalist trend of history writing, those by historians not belonging to Assam but from other parts of India-for example, N.N. Basu (1922, 1926, 1933), S.K. Chatterji (1951, 1955)-who tried to project the Assamese society and culture merely as an extension of the Ganga Valley culture, and thus avoided the minute differences that exist between the Hindu societies of the two regions and also the vast differences that existed among the tribal societies of Assam. The early period of Assam's history has been largely viewed as a Hindu history of Kamarupa, and in the light of the greater Indian history, a sort of a 'singular' history that has been hardly questioned and challenged in any form of history writing in Assam. The existence of a large percentage of non-Hinduised tribal population, and their possible role in the shaping of the history of the region, has categorically been ignored in these writings.

The later period of Assam's history is well represented, thanks to the numerous buranjis. This tradition of history writing of the Ahoms has helped immensely in outlining the chronological development of the Ahom dynastic rule of almost 600 years, beginning from the early part of the 13th Century CE. The role of the Department of Historical and Antiquarian Studies, Assam, in bringing out this storehouse of historical source material to public knowledge is immense. Many of these buranjis were edited and revived by S.K. Bhuyan, an exemplary contribution, indeed. The other kingdoms or principalities that existed during this period have also been studied, although to a lesser extent. For details, see Gait (1906), Gogoi (1968), Guha (1983b), etc. However, a general tendency has been observed among historians, who tend to project this entire period of Assam's history as being that of the Ahoms. The importance of the other two major kingdoms, that of the Kacharis in the eastern part and the Koch kingdom in the western part of Assam.

The theoretical framework of the discipline of history has undergone tremendous changes in the last 50 years. Not merely limiting their views to factual claims, historians today are concerned with a much wider range of issues. Attention has been given to the narrative, fictional and aesthetic 
aspects of history writing, while the issues have spread to ethical, political and ideological components. A variety of non-academic ways of dealing with the past has also been tried; studies related to memory-individual as well as groupare among the most notable examples of such approaches. As the trends have been changing, the scope of history has also spread and multidisciplinary approaches are being considered more and more. On the importance of multidisciplinary approach, Funari et al., (1999: 9) write:

There have been methodological debates regarding giving priority to written source or material source. Such debates have recently been undermined as a new multidisciplinary methodology has taken over. Introduction of oral history has also a part in this.

The importance of archaeological sources, in the above context, thus can be considered as extremely valuable and necessary for a holistic understanding of history. Archaeological records should be considered as integral to historical methodology, as opposed to the general trend among historians to treat these as mere corroborative or supporting evidence. Archaeological records, again by itself, do not lead us to a complete understanding of the past. Without a context, and more a historical and geographical context, archaeological records do not take us much further in our understanding. Hence, the methodology should be a cohesive one, which would include the existing evidence through every possible theoretical approach. Whatever said and done, the fundamental difference between archaeological sources to those of historical lies in the very nature of the records. While historical records are heavily dependent on the dynastic and chronological understanding of the past, archaeological remains lead us to a reconstruction of the material culture of the societies, and thus to a 'subaltern' cultural history. Is it possible to carry out such a holistic study in Assam and thus reconstruct the way the historical phase is looked at or viewed? This is the basic parameter that this paper seeks to examine.

\section{The Problem of Periodisation}

The historical writings of Assam have more or less followed the basic periodisation of Indian history: Early Historical Period (600 BC to $400 \mathrm{CE}$ ), Late Historical Period (400 CE to $700 \mathrm{CE}$ ), Early Medieval Period ( $700 \mathrm{CE}$ to $1200 \mathrm{CE}$ ), and Medieval Period
(1200 CE to the Colonization Period). There is no apparent difficulties whatsoever in following this specific periodisation in order to understand the dynastic history of Assam. Problems occur when we start seeking answers to certain questions in order to understand the socio-cultural formation of the Northeast and the dynamics involved among the various communities through various phases.

The absence of an early historical phase is an intriguing problem in the history of Assam. The earliest written evidence of the Northeast is dated to the 4th Century CE, that is, the famous Allahabad Prasasti of the Gupta Emperor Samudragupta, where Kamarupa and Davaka are mentioned as two independent frontier kingdoms of the Guptas. Kamarupa was the ancient name of Assam, while Davaka can be identified with another kingdom/principality that existed in the KopiliJamuna valley, a southward extension of the Brahmaputra valley in the middle of Assam. Archaeological excavations have so far been unable to provide any absolute date for any of the sites of historical importance, while no epigraphic records from Assam can be dated beyond 5th Century CE. Thus, with the present available knowledge, we will not be able to push back the history of Assam beyond 4th Century CE. Thus, it seems a contemporary period to the Early Historical Phase of Indian history was totally absent in Assam. Does it mean while the northern Indian Ganga valley witnessed the second urbanisation (Gupta 1973) and a full-fledged development of state formation which culminated with the formation of the Mauryan Empire and spread of Buddhism even to foreign countries, Assam still had a rudimentary phase of cultural development, more specifically a continuation of the early farming Neolithic period? The answer is difficult to gauge at present due to the lack of sufficient archaeological evidence and problem-oriented multidisciplinary research.

There is not enough textual as well as epigraphic evidence to fully understand the transition phase from late historical to medieval period of Assam. For convenience of explanation, historians have tended to distinguish the two with the arrival of the Ahoms in the Brahmaputra valley, in the year 1228 CE. The Ahoms came with a tradition of recording the important political events, known as buranjis in local parlance, along with their expansionist zeal. The buranjis provide us with authentic written evidence to easily reconstruct the history of the entire period of Ahom rule, and also of some of the other contemporary kingdoms. However, the lack of 
evidence on the decline or dissolution of the Kamarupa kingdom is an intriguing problem that the historians have to face. We also do not have sufficient evidence to reconstruct the phases when the kingdoms of the Kacharis, the Chutiyas, the Morans and the Borahis, and also the kingdom of Tripura, came into existence, and thus rely on local beliefs, folktales, and even individual and group memory to construct any inference in this regard. In such circumstances, the early medieval phase of Assam remains far from clear, although scholars have tried to understand and explain the same in the light of archaeological evidence in the form of sculptural and architectural remains and copperplate land grants. A scholarly discussion between Amalendu Guha and Nayanjot Lahiri on the preAhom roots of the state formation process of Assam in the journal Social Scientist is notable, as both of them have tried to see the transitional phase from a more multidisciplinary point of view, and have highlighted the differences between the tribal subsistence pattern and the mainstream economy and the role these differences could have played in the state formation process. ${ }^{1}$ Gupta's discussion on the trade network of Assam also throws light on a yet unexplored aspect of trade and economy and their importance in the development of the state in Assam (Gupta 1991). Momin's research on the political and socio-economic history of pre-Ahom Assam is also notable and brings fresh light into this apparently dark period of Assam's history (Momin 1998).

There is another problem in stating that the medieval period began with the arrival of the Ahoms. Mere availability of the buranjis cannot and should not be the marker of this entire period to be belonging to the Ahoms. The Kachari kingdom existed for most part of this period as an independent kingdom, always entangled in a tussle for supremacy with the Ahoms and sometimes even the more dominant-definitely until the middle of the 15th century. Historians, at times, tend to undermine the existence of a strong Koch kingdom in the western part of Assam bordering Bengal. It was under the patronage of Koch King Naranarayan that the Vaisnavite guru Srimanta Sankardeva

\footnotetext{
${ }^{1}$ This argument between Amalendu Guha and Nayanjot Lahiri started with the article published by Guha in Social Scientist, Vol.11 (1983a), which was followed by Lahiri's article in the same journal (1984). Guha's response to Lahiri's review was published in the December issue of the same journal (1984).
}

preached his religious as well as socio-cultural messages. The role of Sankardeva in the formation of the Assamese society is immense and itself is a topic of extended research. The point that needs emphasis here is that the Koch kingdom had been an integral part of the Assamese identity through the medieval times, and Assamese historians so far seem to have undermined or neglected its role in the history of Assam.

The social set-up of Northeast India is very complex, so much so that the scholars have often tended to describe it as a 'mini India'. There is paucity of data to examine the symbiotic relationship that must have been there between the Tibeto-Burmese and the Indo-European populations. The process of assimilation between the people belonging to these two major linguistic groups started quite late in this region, and was at the early stages even during the latter part of 19th Century. The 1881 Census of Assam, which was the first exhaustive census done on this part of India, recorded the population on the basis of religion and caste and revealed that many of the dominant communities like the Bodos and Karbis were still not considered to be within the Hindu fold (Assam Census Report, 1881, pp. 22-34; pp. 63-102; cf. Guha 1974: 107). This gives an entirely contrasting picture of the society as against the majority historians' view that the society of Assam was largely Hindu that flourished as part of the Kingdom of Kamarupa. This leads us to surmise that the historical framework that we derive from textual evidence as well as epigraphic sources has so far undermined the role of the tribal communities in the formation of the Assamese society through the historical period. It has more or less remained the dynastic history of Kamarupa. The 1881 Census reports also present an entirely different picture as against the popular belief that the Assamese society was unified sans religious and ethnic boundaries under the socio-religious movement (the neo-Vaisnavite movement) preached by Sri Sankardeva and later by his followers since the 15th Century.

In such a situation, we need to re-examine the sources of history and try to understand the many local histories of the various communities in Assam as well as its adjoining regions. Archaeological sources, including excavation finds and ethnographic records, will help in reassessing this. The status of the archaeological work done so far in the Northeast will be examined in the following in the light of its importance in reassessing the 
chronology of the historical phase of Northeast India.

\section{Importance of Archaeological Records}

The new trend of Historical Archaeology focuses more on 'archaeological study of all human societies in terms of interdisciplinary theories of material culture, but also recognises the methodological distinctiveness of studying societies with written sources' (Funari et al., 1999: 8). Following this new Historical Archaeology, it has been felt that the historical phase of Northeast India, too, needs to be reviewed and analysed with a paradigm shift in terms of methodology, and the traditional periodisation needs to be verified and examined from an archaeological point of view. However, keeping the paucity of material evidence into consideration, a modest attempt has been made here to come up with a possible periodisation of the historical phase of Northeast, especially Assam.

There has been three major archaeological excavations on sites of historical importance in the Northeast-the Ambari excavation in Assam, for one season in 1971 and then for three seasons from 1997 to 2000; the Sekta burial site excavation in 1991 in Manipur; and the Vadagokugiri/Bhaitbari excavation in 1992 in Meghalaya. Apart from the Ambari excavation, the details of the other two are found in printed reports (Sharma 1993, 1994). The Directorate of Archaeology of Assam has, however, brought out an interim report of Ambari excavation (Dutta 2006), which includes published articles and preliminary reports on various aspects of the historical site. Apart from these three sites, minor excavations or rather section analyses have been done in some sites in the Dhansiri-Doyang valley in Assam (Choudhury 1994, Dutta 1995), some sites in Arunachal Pradesh, Tripura and Nagaland-all of which have been reported in various issues of Indian Archaeology-A Review, published by the Archaeological Survey of India. The archaeological work done at the site of Mahasthangarh in Bangladesh is also important in order to understand the historical dynamics, owing to its strategic geographical positioning and being contiguous to the Brahmaputra valley (Alam and Salles 2001).

The site of Ambari, situated in the centre of Guwahati city, has been unanimously identified with the city of Pragjyotisa, the capital city of Kamarupa; although no absolute dating or any typifying artifacts have been obtained which can prove the inferences beyond any doubt. The stratigraphic sequence of Ambari has shown the occurrence of Neolithic strata below the historical phase, which could not be studied due to the rising level of groundwater. The material evidence shows a rich and developed society which saw the development of art and architecture of high skills. The pottery is uniform and does not show many varieties (Goswami and Roy 2006; Sharma et al., 2006; Sonowal 2006). It is difficult to ascertain a date for the site of Ambari merely on the archaeological evidence, but can be easily surmised that the earliest period of the historical phase at the site does not go beyond 4 th-5th centuries CE. The sculptural remains mainly conform to this period if not earlier and post-Gupta traits are apparently visible, however with minor local variations. The pottery cannot be dated as no comparative pottery has been found elsewhere that has been dated.

The site of Sekta in Manipur has provided a lot of burial remains, which are associated with pots. The habitation site at Sekta has been destroyed and could not be excavated. The burial site, however, has yielded invaluable cultural material ranging from urn burials to a variety of artifacts (Sharma 1994: 23-26). The site of Sekta is very crucial in our understanding of the historical phase of Northeast India, as the cultural material here shows definite connection between people of this part of India with those of mid-Ganga valley as well as from South China and Myanmar. The site is also significant in our understanding of the trade network between India and China via the land-route of Myanmar and South China (Gupta 2006, Sarma 2006b).

The site of Vodagokugiri or Bhaitbari in Garo Hills, Meghalaya is very important as it is situated in the fringes of the Brahmaputra valley near Bangladesh, and is very near to the famous site of Mahasthangarh in Bangladesh, supposedly the capital city of the Pundravardhana kingdom of early medieval Bengal. The site layout and the material remains also show affinity to those of Mahasthangarh. Although no dates have been obtained from Vadagokugiri, a relational analysis with that of Mahasthangarh will safely put this site in the same period. However, we need to still understand the historical importance of this site as far as the Kamarupa kingdom is concerned; it is not clear whether this area belonged to the Kamarupa kingdom or Pundravardhana on the basis of the material remains. It is important to note that traits of Jaina influence have been observed in the architectural remains of Suryapahar. However, this 
needs further examination as such a finding would entirely open a new dimension in understanding the history of Assam (Shastri 2000). It is interesting to note that when Hiuen Tsang visited the Kamarupa King Bhaskara Varman, he observed that people of this country did not believe in Buddhism (or Jainism for that matter) and there was no dedicated place of worship for that faith. Jainism, even in the modern period, is barely present in Assam. Hence, the claims of Jaina elements being discovered from Vadagokugiri need a fresh look.

Notable work has been done in the DhansiriDoyang valley. H.N. Dutta of the Directorate of Archaeology has recorded many sites in the valley and has surmised the prevalence of an independent kingdom there on the basis of epigraphical evidence (Dutta 2000). The earliest date of this independent kingdom could be assigned to the 5th Century CE on paleographic grounds. Sarma (2006a) carried out further studies in the valley on the premises of settlement pattern and did a systematic recording of the available archaeological record. He, corroborating the archaeological record with literature and geography has identified the archaeological remains of the valley to be belonging to the Kacharis, who saw tremendous socio-cultural development before the arrival of the Ahoms and became the rulers of this area much earlier, probably contemporary to the Kamarupa kingdom, and had independent status for a long period.

\section{A Chronology for Assam's Historical Past}

The available evidence-archaeological as well as textual-does not give a date prior to the 4 th Century CE for the beginning of the history of Assam. Thus, from a pan-Indian viewpoint we are bound to state that the early historic period of the conventional periodisation of Indian history is totally absent in this part. Likewise, the state formation process also started here in the 4th Century CE only. Some scholars have tried to explain mythological inferences and tried to relate the legends of Narakasura and Bhagadatta with the earliest form of state formation in Assam. However, it is our firm belief that the danger of using myths as historical evidence has to be acknowledged and thus myths should not be considered as facts. It is time we acknowledge that history can be considered as facts only if we draw it with supporting evidence, not inferences. ${ }^{2}$

It is essential to acknowledge that the historical phase started late in this region as compared to that of the Ganga Valley. The paucity of written evidence is a clear marker when we posit this view. The late migration of the Indo-Europeans, especially the Indo-Europeans from the Ganga Valley, into the Brahmaputra Valley, could be a reason why the historical phase began late in the region. However, that does not necessarily mean that the tribal populations did not have developments, which can be called historical. However, such a possibility also remains in the realm of surmise due to lack of proper textual as well as material evidence. In fact, the local histories of the tribal populations in these early years are entirely based on myths and legends and thus cannot be considered as authentic historical evidence. More archaeological and similar supporting evidence will be required to authenticate this aspect. Hence, to properly understand and explain this period, we would suggest, it should not be classified from a panIndian viewpoint.

The same holds true for the classification of the medieval period; for the available evidence do not suggest any major shifts or change in the socio-cultural set-up through the entire period of the history of the region. The arrival of the Ahoms should not be the sole marker of dividing this phase from the earlier phase of history. Northeast India, especially the Brahmaputra Valley, saw a uniform development in the entire period of its history. However, for convenience of explanation in history writing,

\footnotetext{
${ }^{2}$ See Megill (2007) for a detailed discussion on what can be called historical evidence. Megill cautions the serious historian about the dangers of inferences or assertion through his critique of a 2003 American Historical Review article by William G. Thomas III and Edward L. Ayers in which the authors claim to show "by argument" something important about the way slavery brought about the American Civil War. Megill writes that contrary to what Thomas and Ayers claim, they "do not make an argument at all." He further argues that Thomas and Ayers "fail to understand what is required for something to be evidence for something else" (quoted in, Martin 2010).
} 
the entire period can be classified into three periods, although without any characteristic dividing marker or events between them:

- Early phase: This phase marks the beginning of the state formation process, the earliest evidence of which can be found in the Allahabad Prasasti. Several independent states came up in various parts of the region, for instance the Kamarupa kingdom in lower Assam and the Dabaka kingdom in central Assam, both in the southern bank of the Brahmaputra. Other small kingdoms or principalities came into existence in the Dhansiri-Doyang valley as well as in the Sadiya region in the north eastern corner of the valley. In course of time, the Kamarupa Kingdom became powerful and controlled a large area from the eastern hills to the Bay of Bengal, as can be known from the accounts of Hiuen Tsang. This phase also saw the rise of the three main dynasties of the Kamarupa Kingdom-the Barmans, the Salastambhas and the Palas-who patronized the spread of the Hindu religion in the valley.

- Transitional phase: The rise and the gradual decline of the petty kingdoms of the Tibeto-Burman speaking communities, more or less, cover this transitional phase of Assam's history. The rise of these kingdoms incidentally coincides with the decline of the Kamarupa kingdom, the Pala dynasty to be more precise. The Kamata kingdom came into existence on the ruins of the Kamarupa Kingdom, especially in the western part of the Brahmaputra Valley (Gait 1906). We also have a few epigraphs of the early rulers of the Kamata Kingdom to support this view (Sarma 1981). In the meantime, the Chutia and the Kachari Kingdoms also rose into prominence in the eastern part of the Valley. We have paucity of textual as well as epigraphical evidence to reconstruct the early phases of these Kingdoms, but archaeological sources may provide us with significant evidence (Sarma 2006a). The socio-cultural and economic scenario during this phase remains an area that needs further multidisciplinary research.

- Late Phase: The late phase of Assam's history is marked by three important events: first, the arrival of the Ahoms and their gradual assimilation into the greater Assamese society and the consequent formation of a formidable state in the heart of Assam; second, the rise of the Koch kingdom in the west and many petty principalities of the Bhuyas in the central region of Assam, as well as the strong existence of the Kachari Kingdom in the Dhansiri and Kopili Valleys in the south of the Brahmaputra; and third the rise of the neo-Vaisnavite religious movement preached by the Mahapurush Srimanta Sankardeva in the 15th Century CE (Neog 1965) that would change the socio-cultural complexion of Assam entirely and also influence subsequent politico-social movements such as the Moamoria Movement that eventually threatened the very existence of the Ahom monarchy. The coexistence of two powerful state mechanisms in the west and the east eventually led to different landholding and revenue systems in the two distinctive regions (Guha 1991). The administration of the western part also remained under the Mughals for a considerable period in the 17th Century CE, which also contributed to the difference in landholding and administrative systems.

Many parts of Assam and other adjoining areas, until the beginning of its historical period, that is, the 4th Century CE, must have remained under the Neolithic, early farming phase. However, the two excavated Neolithic sites in Assam, that is, the Daojali Hading and the Saru-Taro, do not present any evidence of continuity to the historical phase. But the fact that the 'Neolithic'/early farming phase continued through the historical phase in isolated pockets 
can be safely put forward on the grounds of oral traditions and memory of certain tribal populations in the region. In many of the tribal villages, people still refer to an old village, which is invariably in an isolated area in the foothills. Some of these deserted villages may not be even one hundred years old. In case of certain communities like Karbi, Garo and Tiwa, people often speak about a tradition of elaborate stone memorials (often misinterpreted as Megalithic stone burials), which they practiced till recent times but has now remained only in symbolic form. Although hypothetical, it can be surmised that sections of people lived in isolated pockets until late into the 19th century and remained outside the process of cultural assimilation with the IndoEuropeans for a long time. There is no recorded archaeological evidence to prove that these people were practising a Neolithic lifestyle. However, the fact that they lived in a community-bound social set-up and practised the traditions of early farming societies is certain.

In order to analyse this coexistence of Neolithic phase with that of a highly developed State within the Hindu fold in the light of the nature of interaction between the two and the impact this had on the socio-cultural complexion of the Northeast, we need to compare the distribution pattern of the archaeological sites of both the cultural phases. The tentative distribution pattern of both these phases shows a clear demarcation though. While the historical sites are scattered mostly in the valley areas, the Neolithic sites have been found mostly in the foothills of the mountains surrounding the Brahmaputra Valley and in some cases in the Shillong plateau (Sarma and Hazarika 2014). However, to testify any hypothesis on this particular issue, a detailed and multidisciplinary research will be the first priority. Corroborative evidence from linguistics, folklore and ethnography may also help in this.

It is obvious that the recorded history of Assam, be it the early phase or the later phase, do not speak about the population living in the hills; in fact, it is mainly confined to the dynastic achievements of the various kingdoms, mostly the Kamarupa Kingdom. It is an urgent need that a problem-oriented research be done in order to record these local histories, from whatever source is available now. Ethnographic studies on these communities have been done, but these have not been highlighted so far. Folklore is another aspect, which may lead us to many unknown facts of these communities. Toponymical studies have also great potential in understanding the prevalence and distribution of various tribes and also the process of social and cultural assimilation and admixture through the ages. Reviewing and carrying out intensive investigations based on earlier works like that of Peal (1879) will surely provide meaningful and interesting results.

\section{A Note on the Kacharis}

The representation of the Kacharis in the history of Assam has been an enigmatic issue. They have been sometimes described as the makers of the Hinduised Kamata or the Koch Kingdoms in the western part of Assam; while at some other, times have been associated with the Kachari Kingdom, which ruled in a vast tract from the foothills of Nagaland to the Kopili-Jamuna Valley, the Dhansiri-Doyang Valley forming the heart of their Kingdom. It is clear, in our current understanding, though, that the western Kamata and the subsequent Koch Kingdoms were founded by the Mech or the Koch communities, who are a Hinduised branch of the greater Bodo community of Assam. Likewise, the Kachari Kingdom of the Dhansiri-Doyang Valley was founded by the Dimasa Kacharis, another community that speaks a language belonging to the Tibeto-Burman linguistic sub-group of the Sino-Tibetan language family, like that of the Bodos. At present, two important divisions among the Kachari population of Assam can be seen-the Bodos (plain Kachari) and the Dimasas (hill Kachari). Both linguistically and culturally there can be seen sharp contrasts and differences between these two groups at present. Yet, while referring to the Kacharis, all the medieval chronicles as well as the colonial administrator-historians have failed to clearly 
distinguish between these two as well as the other Kachari communities of Assam.

Hunter's Statistical Account of Assam (1879) and the 1881 Census are important in many respects. The Census of 1881, covering the length and breadth of the Valley, recorded the communities of the greater Bodo-Kachari group as separate ethnic groups. It documented 19 such communities: Bodo, Dimasa, Dhimal, Garo, Hajong, Hojai, Lalung, Madani, Mahalia, Mech, Matali, Moran, Phularia, Rabha, Sonowal, Sutiya, Saraniya, Solamiya, and Tipra, which formed the majority population in the whole of the Brahmaputra Valley, followed by the Kalitas, and then the Daibagnas and the Brahmanas. The Koches and the Rajbanshis were also included in the Bodo-Kachari group, but were considered as totally Hinduised tribes. Most of these Bodo-Kachari communities, classified in the 1881 Census, have now merged with the greater Assamese speaking society, only scantily retaining their original speech.

A concerted effort to knowing the individual histories of the various groups of the BodoKachari communities have not come into sight, at least to the knowledge of the present author. That apart, the colonial historiographical tradition as well the nationalist historians have also failed to contribute to the knowledge of the early history of these communities adequately. Instead, many a historians have actually displayed and presented conflicting accounts and have confused with the identity of a particular tribe to another. An example of this is Endle's otherwise brilliant account of the Kacharis-mainly the Bodos of the northern plains of Assam (1911). Endle, while drawing the historical background of the Kacharis (Bodos in his case) have mistakenly identified the Chutiyas and the Kacharis as the same people. While referring to the defeat of the Chutiyas at the hands of the Ahoms, Endle states:

...In the end the victory remained with the Ahoms, who drove their opponents to take refuge in or about Dimapur on the Dhansiri at the foot of the Naga
Hills. There for a time the fugitives were in comparative security...[but] their ancient foes followed them up to their new capital, and about the middle of the sixteenth century the Ahoms succeeded in capturing and sacking Dimapur itself. (Endle 1911: 6)

That the Chutiyas and the Kacharis had separate Kingdoms, around Sadiya and in the Dhansiri Valley respectively, was obviously over-sighted by Endle, a fact which would eventually be established owing to the recorded chronicles of the Ahoms, the buranjis. In the above narration, Endle's obvious confusion between the two distinct communities may create historical errors. Apart from the buranjis, not many historical accounts have been successful in bringing out individual histories of these communities, a fact that needs serious reconsideration of the present lot of historians in Assam.

The point that needs emphasis here is that the Kacharis (including the largest group Bodos) were the most dominant population in the Valley throughout its history. That they were once very influential too, can be gauged from the fact that most of the place and river names of modern Assam continue to be that of Bodo origin. The prefix $D i$, meaning water in Bodo languages and dialects are invariably used in naming most of the rivers and places in Assam (e.g. Di-bru, Digboi, Disang, Dihang, Dikhou, etc.). The river Brahmaputra was also earlier known as Ti-lao or Di-lao.

Notwithstanding the current differences among the various Tibeto-Burman communities, there are reasons to believe that once upon a time, such divisions were not so distinguishable. Two characteristic similarities among these groups are conspicuous:

- All these groups speak dialects and languages belonging to the TibetoBurman (TB) language sub-group of the Sino-Tibetan Family. This takes us back to a single parentage to this entire group, which probably had originated in 
the southern province of Sichuan in China in the prehistoric times.

- All these groups (barring the Bodos of Western Assam), until recently, used to pay an annual homage or tribute to the Kesaikhaiti Gosani Temple at Sadiya. This proves a single lineage of these various tribes, a religious knot to say more precisely.

The difference between the Bodos and the Dimasas is sharp at present. Traditions, however, indicates a single root to both. They have a similar tradition of the origin of the universe, which speaks of a flood and the subsequent creation of the earth. There is another tradition among the Bodos, which speaks of the existence of two groups, one of which happened to cross a big river because of some disputes. It seems probable that the Bodos were the ones who crossed the river and settled down on the foothills of the Himalayas and later were disowned by the Dimasas, who initially settled on the foothills of the Patkai, the Naga Hills and the Dhansiri and Kopili Valleys. In all likelihood, they entered the Brahmaputra Valley through the Patkai Hill Range.

This is, perhaps, the most intriguing issue, which eventually will dominate the archaeological and anthropological studies in Assam in the coming decades. At this juncture, however, certain questions may arise which may even baffle the most scrutinising minds. Is it possible with the current state of documentation, combined with a serious lack of historical sense of the tribal communities themselves, to draw individual histories for each of these communities? Is it possible that all these communities had a shared history and a single lineage? If at all they had a shared lineage, when did the separation begin and became so distinct that at present it is almost impossible, both culturally and linguistically, to link one community with the other; say for example the Bodos and the Dimasas? Was there any major outside influence? The antiquity of the Kacharis, it has been felt, is one of the most essential aspects of the history of Assam, which needs further research to understand the early history of Assam as well as the socio-cultural development of the multifaceted society of Assam. The Kacharis should not and cannot remain an enigma, but be brought into the forefront of the mainstream historical tradition.

\section{Concluding Remarks}

An authentic reconstruction of the ancient history of Assam is as daunting task as writing a unilateral history for the whole world. The cultural composition of Assam is such that there is always a great danger of falling short in this responsibility. There are many local histories; as many, or even more, as there are distinctive communities within the greater cultural fold of Assam. Unless authentic documentations of these local histories are made, writing an all-encompassing history for Assam will continue to be difficult. Serious efforts in this regard should be made a priority. There is also a serious need to understand what forms an evidence for history writing and what does not. Over-dependence on quasi-historical sources such as the Puranas and the classical literature as well as myths will lead to nowhere, but will rather create further historical 'errors'. Unless a multidisciplinary approach is taken up for research into the past, which will include associated disciplines such as archaeology, anthropology, folklore and geography among others at both theoretical and the methodological levels, the history of Assam will continue to be either a 'historical myth' or, for the worse, a 'mythological history'.

\section{References:}

Alam, Md. Shafiqul and Jean-Francois Salles. 2001. 'France-Bangladesh Joint Venture Excavations at Mahasthangarh: First Interim Report, 1993-1999,' Department of Archaeology, Bangladesh.

Barua, B.K. 1951. A Cultural History of Assam (Early Period), Vol.1. Madras: G.S. Press.

Barua, B.K. 1952. Early Geography of Assam. Madras: G.S. Press. 
Barua, K.L. 1933. Early History of Kamarupa (Reprinted in 1966). Guwahati: Lawyer's Book Stall.

Basu, N.N. 1922. Social History of Kamarupa, Volume I. Calcutta: The Jain Siddhanta Prakashak Press.

Basu, N.N. 1926. Social History of Kamarupa, Volume II. Calcutta: The Jain Siddhanta Prakashak Press.

Basu, N.N. 1933. Social History of Kamarupa, Volume III. Calcutta: The Jain Siddhanta Prakashak Press.

Chatterji, S.K. 1951. Kirāta Jana Krti: The IndoMongoloids: Their Contribution to the History and Culture of India. Calcutta: The Asiatic Society (Reprinted in 1974).

Chatterji, S.K. 1955. The Place of Assam in the History and Civilisation of India. Madras: G.S. Press.

Choudhury, N.D. 1994. 'Report of the Archaeological Exploration and Excavation in Dhansiri Sub-division of Golaghat District of Assam,' Journal of Assam research Society, 33 (2): 85-92.

Choudhury, P.C. 1959. The History of Civilisation of the People of Assam to the Twelfth Century $A D$. Guwahati: Spectrum Publications (3rd Ed in 1987).

Endle, Sidney. 1911. The Kacharis. Macmillan and Co. Available online at: archive.org/details/kacharis009491mbp (accessed on 30.12.2012).

Dutta, H.N. 1995 (published in 2001). 'A Report on the Archaeological Excavation conducted in the state of Assam during the year 1997-98,' Journal of Assam Research Society 34 (1 \& 2): 251-61.

Dutta, H.N. 2000. 'Archaeological Importance of Doiyang-Dhansiri Valley of Assam,' Puratattva, 31: 92-97.

Dutta, H.N. (ed.). 2006. Ambari Archaeological Site: An Interim Report. Guwahati: Directorate of Archaeology Assam.
Funari, P.P.A., S. Jones and M. Hall. 1999. 'Introduction: Archaeology in History,' in Historical Archaeology: Back from the Edge (P.P.A. Funari, M. Hall and S. Jones eds), pp. 120. London: Routledge.

Gait, E.A. 1906. A History of Assam. Calcutta: Thacker, Spink \& Co.

Gogoi, Padmeswar. 1968. The Tai and the Tai Kingdoms, Guwahati: Gauhati University.

Goswami, M.C. and S.K. Roy. 2006. 'A Report on Selected Potsherds from Ambari archaeological Site,' in Ambari Archaeological Site: An Interim Report (H.N. Dutta ed.), pp. 27-29. Guwahati: Directorate of Archaeology Assam.

Guha, Amalendu. 1974. 'Geography behind History,' in Science and Human Progress (D.D. Kosambi Commemoration Volume), pp. 87-116. Bombay: Popular Prakashan.

Guha, Amalendu. 1983a. The Ahom Political System: An Enquiry into the State Formation Process in Medieval Assam (1228-1714). Social Scientist, Vol. 11 (December): 3-34.

Guha, Amalendu. 1983b. The Ahom Political System. Calcutta: Centre for Studies in Social Sciences.

Guha, Amalendu. 1984. Pre-Ahom Roots and the Medieval State in Assam: A Reply, Social Scientist, 12(6): 70-77.

Guha, Amalendu. 1991. Medieval and Early Colonial Assam: Society, Polity, Economy. Calcutta: Centre for Studies in Social Sciences.

Gupta, Chitrarekha. 1991. 'Trade and Markets of North-Eastern India: The Ancient Period,' in Archaeology of North-Eastern India (Jai Prakash Singh and Gautam Sengupta eds.), pp. 280-99. New Delhi: Vikas Publishing House Pvt Ltd.

Gupta, S.P. 1973. 'Two Urbanizations in India: A Side Study in their Social Structure,' Puratattva, no. 7: 53-60.

Gupta, Sunil. 2006. 'Indo-Chinese Crosswords: The Assam-Yunnan Axis in the Indian Ocean Interaction Sphere $\left(1^{\text {st }}-5^{\text {th }}\right.$ Century CE),' Journal of Indian Ocean Archaeology, No.3: 90-107. 
Hunter, W.W. 1879. A Statistical Account of Assam. Available online at: archive.org/details/statisticalaccou01huntuoft (accessed on 30.12.2012).

Lahiri, Nayanjot. 1984. 'The Pre-Ahom Roots of Medieval Assam,' Social Scientist, 12 (6), June: 60-69.

Majumdar, R.C. (ed.). 1964. A History and Culture of the Indian People, Volume 4. Mumbai: Bharatiya Vidya Bhawan.

Martin, Raymond. 2010. 'Let Many Flowers Bloom: Review of Historical Knowledge, Historical Error, by Allen Megill,' History and Theory, 49 (October): 426-34.

Megill, Allen. 2007. Historical Knowledge, Historical Error: A Contemporary Guide to Practice. Chicago: Chicago University Press.

Momin, M. 1998. 'Studies in the Political and Socio-Economic History of Pre-Ahom Assam: Perspectives and Prospects,' North Eastern Hill University Journal of Social Sciences and Humanities, 1(1), January-June: 1-3.

Mukhia, Harbans. 1998. "Medieval India”: An Alien Conceptual Hegemony?' The Medieval History Journal, 1(1): 91-105.

Neog, M. 1965. Early History of the Vaisnava Faith and Movement in Assam. New Delhi: Motilal Banarasidas (reprinted in 1985).

Peal, S.E. 1879. 'A Peculiarity of the River Names in Asam and Some of the Adjoining Countries,' Journal of Asiatic Society of Bengal, 47: 258-70.

Raychaudhuri, H.C. 1923. Political History of Ancient India: From the Accession of Parikshit to the Extinction of the Gupta Dynasty. Calcutta: University of Calcutta (7th Edition, 1972).

Sarma, D. (ed.). 1981. Kamarupasasanavali. Guwahati: Publication Board Assam.

Sarma, Pranab Jyoti. 2006a. Archaeology of Early Settlements of Dhansiri-Doyang Valley, Assam: A Study in Regional Perspective. PhD Thesis submitted to Deccan College Postgraduate and Research Institute, Pune.
Sarma, Pranab Jyoti. 2006b. 'Roles Played by Two River Valleys of Assam in the Indo-Chinese Trade Network,' Journal of Indian Ocean Archaeology, No. 3: 108-16.

Sarma, Pranab Jyoti and Manjil Hazarika. 2014. 'Situating Northeast Indian Archaeology in Chronological Perspective: Fresh Observations,' in 50 Years after Daojali-Hading: Emerging Perspectives in the Archaeology of Northeast India-Essays in Honour of Tarun Chandra Sharma (Tiatoshi Jamir and Manjil Hazarika Eds.), pp. 37-59. New Delhi: Research India Press.

Sharma, A.K. 1993. Emergence of Early Culture in North-East India. New Delhi: Aryan Books International.

Sharma, A.K. 1994. Manipur: The Glorious Past. New Delhi: Aryan Books International.

Sharma, H.C., A.A. Ashraf and H.C. Mahanta. 2006. 'Ceramic Tradition in Brahmaputra Valley, Assam: A Case Study from Ambari, Guwahati,' in Ambari Archaeological Site: An Interim Report (H.N. Dutta ed.), pp. 45-57. Guwahati: Directorate of Archaeology Assam.

Shastri, A.M. 2000. 'Bhaitbari Excavations-A Reappraisal,' Puratattva, 31: 79-83.

Sonowal, M. 2006. 'A Brief Report on the Potteries of Ambari Excavation, Guwahati-1, Kamrup, Assam,' in Ambari Archaeological Site: An Interim Report (H.N. Dutta ed.), pp. 83-86. Guwahati: Directorate of Archaeology Assam.

Sreedharan, E. 2000. A Textbook of Historiography. New Delhi: Orient Longman.

Thaper, Romila. 1966. A History of India, Volume 1. London: Penguin Books (Revised in 1976).

Vasu, N.N. 1922. Social History of Kamarupa, Volume I. Calcutta: The Jain Siddhanta Prakashak Press.

Vasu, N.N. 1926. Social History of Kamarupa, Volume II. Calcutta: The Jain Siddhanta Prakashak Press.

Vasu, N.N. 1933. Social History of Kamarupa, Volume III. Calcutta: The Jain Siddhanta Prakashak Press. 